\title{
Anticancer effects of 7,8-dihydromethysticin in human leukemia cells are mediated via cell-cycle dysregulation, inhibition of cell migration and invasion and targeting JAK/STAT pathway
}

\author{
YI XIAO* \\ TAORAN DENG \\ LIJUN JIANG \\ DI WANG \\ Department of Hematology, Tongji \\ Hospital, Tongji Medical College \\ Huazhong University of Science and \\ Technology, Wuhan, Hubei, 430030 \\ China
}

Accepted October 27, 2020

Published online November 10, 2020

\begin{abstract}
The main focus of this research work was to study the anticancer properties of 7,8-dihydromethysticin against HL-60 leukemia cells. Investigations were also performed to check its impact on the phases of the cell cycle, cell migration and invasion, JAK/STAT signalling pathway and intracellular mitochondrial membrane potential (MMP) and reactive oxygen species (ROS). Cell proliferation was assessed through 3-(4,5-dimethylthiazol-2-yl)-2,5-diphenyl tetrazolium bromide (MTT) assay and effects on colony formation were examined via clonogenic assay. Flow cytometry and Western blott analysis were performed to investigate the distribution of cell cycle phases. Flow cytometric analysis was performed for the examination of MMP and ROS production. The effect on JAK/STAT signalling pathway was examined through Western blot analysis. Results depicted that 7,8-dihydromethysticin induced concentration- as well as time-dependent inhibition of cell proliferation in leukemia HL-60 cells. Clonogenic assay indicated potential suppression in leukemia HL-60 cell colonies. The 7,8-dihydromethysticin molecule also caused cell cycle arrest at G2/M-phase along with concentration-dependent inhibition of cyclin B1, D1 and E. ROS and MMP measurements indicated significant ROS enhancement and MMP suppression with increasing 7,8-dihydromethysticin concentrations. Additionally, 7,8-dihydromethysticin led to remarkable dose-reliant inhibition of cell invasion as well as cell migration. Therefore, 7,8-dihydromethysticin should be considered a valuable candidate for leukemia research and chemoprevention.
\end{abstract}

Keywords: leukemia, 7,8-dihydromethysticin, flow cytometry, cell cycle, signalling pathway

Leukemia is a life-threatening disorder linked to human bone marrow and blood and is associated with huge mortality and incidences worldwide $(1,2)$. The development of this malignant disorder takes place in blood-forming tissues. Patients with leukemia show a

\footnotetext{
*Correspondence; e-mail: yixiao@tjh.tjmu.edu.cn
} 
large number of incompletely developed or immature WBCs $(3,4)$. These immature cells divide to create their copies and resist death caused by cellular damage or age. The frequent division of leukemia cells outnumbers the normal RBCs and erythrocytes, thereby decreasing the oxygen taking capacity of the blood, fighting infection and bleeding control. Pathologically and clinically, leukemia is differentiated into various categories based on the symptoms, history and effected cell types like lymphoblast and myeloid cells $(5,6)$. Based on this, four different types of leukemia have been identified including acute lymphoblastic leukemia (ALL), acute myeloid leukemia (AML), chronic lymphoblastic leukemia (CLL) and chronic myeloid leukemia (CML) $(7,8)$. ALL and AML are identified with higher frequency in children and adults, respectively. Conventional chemotherapeutic agents are usually effective against leukemia but the side-effects associated are much more serious $(9,10)$. The overall survival in leukemia patients post-chemotherapy remains very low due to the high possibility of disease recurrence and deadly side-effects like cardiac events. Thus, there is a pressing need for treatment options for leukemia with reduced side-effects and increased overall survival rates. The HL-60 cell line is a type of human leukemia cells that has been used in laboratory research on physiology and blood formation. These cells proliferate in a suspension culture rich in antibiotic chemicals and nutrients. This cell line is derived from patients with acute promyelocytic leukemia and predominantly exhibit neutrophilic promyelocytic morphology. HL-60 cells are mostly used as a cell model to evaluate pharmacological and physiological effects on myeloid differentiation and other aspects. Natural products are comprised of a huge number of chemicals that pose no threat to naturally balanced systems in humans and also act as potential pharmacological agents (11-15). Naturally occurring Kava plant comprises of different chemical entities including kavalactones. One such kavalactone is dihydromethysticin (DHM), which has been regarded as a remarkable medicinal and pharmacological agent (16). Dihydromethysticin has been reported to exhibit significant activity such as anticancer, anticonvulsant, analgesic and anxiolytic and it acts as a monoamine oxidase B reversible inhibitor and positive $\mathrm{GABA}_{\mathrm{A}}$ receptor allosteric modulator (17-20). The current study was designed to unveil the antitumor activity of 7,8-dihydromethysticin in human leukemia HL-60 cells along with examining its effects on cell cycle progression, mitochondrial membrane potential (MMP), reactive oxygen species (ROS), inhibition of cell migration and invasion and JAK/STAT signalling pathway.

\section{EXPERIMENTAL}

\section{Cytotoxicity evaluation}

Leukemia HL-60 cells were plated onto 96 -well plates and harvested at $75 \%$ of confluence. Plated cells were exposed to different concentrations of 7,8-dihydromethysticin viz. 0, 10, 50, 75 and $100 \mu \mathrm{mol} \mathrm{L}^{-1}$. 7,8-Dihydromethysticin (HPLC purity $\geq 98 \%$ ) was procured from Shanghai Chemical Reagent Co Ltd, China. The time duration of treatment with the currently tested molecule at $37{ }^{\circ} \mathrm{C}$ of incubation varied from 24 and $48 \mathrm{~h}$. Dimethyl sulphoxide (DMSO) vehicle $(0.2 \%, V / V)$ was used as a negative control. Cisplatin (Sigma Aldrich, China) was used as a reference for the positive control. 7,8-Dihydromethysticin treatment was followed by incubation with MTT solution of $0.5 \mathrm{mg} \mathrm{mL}^{-1}$ concentration for $4 \mathrm{~h}$ and $37^{\circ} \mathrm{C}$. The media was completely removed and the extraction of formazan was 
done in DMSO $(200 \mu \mathrm{L})$ at room temperature for $10 \mathrm{~min}$. Finally, the optical density (OD) was recorded with $570 \mathrm{~nm}$ of wavelength and using a microplate reader (BioRad), repeating twice in triplicates.

\section{Colony formation assay}

Leukemia HL-60 cells were cultured in 6-well plates using RPMI-1640 medium augmented with $10 \%$ fetal bovine serum at a density of $3 \times 10^{3}$ each well. Cultured cells were treated with 7,8-dihydromethysticin at variant concentrations of $0,25,50$ and $100 \mu \mathrm{mol} \mathrm{L}^{-1}$, for one week followed by fixation and staining with $4 \%$ paraformaldehyde and $0.1 \%$ crystal violet respectively (Beyotime, China). Utilizing a digital camera, stained cells were photographed and analysed (Olympus, Japan).

\section{Cell cycle phase assessment via flow cytometry}

Flow cytometric analysis for cell cycle phase distribution was performed to leukemia HL-60 cells. These cells were seeded at a density of $1 \times 10^{5}$ cells in each well of 6 -well plates. Seeding was followed by 7,8-dihydromethysticin treatment at changing concentrations viz. 0, 25, 50 and $100 \mu \mathrm{mol} \mathrm{L}{ }^{-1}$ and incubation for $24 \mathrm{~h}$. 7,8-Dihydromethysticin treated cells were then phosphate-buffered saline (PBS) washed and fixed in $80 \%$ ethanol and stored overnight at $4{ }^{\circ} \mathrm{C}$. Afterward, treated cells were again washed with PBS and subjected to 5 $\mu \mathrm{g} \mathrm{mL} \mathrm{L}^{-1} \mathrm{RNase}$ and propidium iodide $\left(20 \mu \mathrm{g} \mathrm{mL} \mathrm{m}^{-1}\right.$ of PI) staining at $37^{\circ} \mathrm{C}$ in a dark room for half an hour. Finally, cell cycle analysis was performed with a flow cytometer (FACScan; NJ, USA) and DNA content was collected for cell cycle phase distribution with ten thousand cells per sample.

\section{ROS and MMP analysis by flow cytometry}

Leukemia HL-60 cells were subjected to staining with fluorescent dye tetramethylrhodamine methyl ester (TMRM) and analysing with a flow cytometer for MMP assessment. After treatment with different 7,8-dihydromethysticin concentrations $(0,25,50$ and $100 \mu \mathrm{mol} \mathrm{L}-1)$ cells were stained in the dark with TMRM $\left(200 \mu \mathrm{mol} \mathrm{L}^{-1}\right)$ in PBS for about 15 min at $37^{\circ} \mathrm{C}$. Orange fluorescence intensity was recorded and analysed using flow cytometry. For ROS estimation, leukemia HL-60 cells were harvested from 96-well plates and subjected to 7,8-dihydromethysticin treatment at variant concentrations viz. 0, 25, 50 and $100 \mu \mathrm{mol} \mathrm{L}{ }^{-1}$. Afterward, cells were washed twice with Hanks' Balanced Salt Solution (HBSS) followed by staining with Dihydroethidium staining (DHE) $(100 \mu \mathrm{L})$ for half an hour at $37^{\circ} \mathrm{C}$. DCF fluorescence with each cell was obtained by capturing, extracting and analysis through Data Viewer version 3.0 and ArrayScan II Data Acquisition (Cellomics).

\section{Determination of cell migration through transwell chambers}

Transwell chambers (Corning Costar, USA) were used to carry cell migration analysis of Leukemia HL-60 cells after 7,8-dihydromethysticin treatment. Briefly, upper chambers were filled with media and Leukemia HL-60 cells at a concentration of $2 \times 10^{3}$ cells each upper transwell chamber and only the medium was placed in lower chambers for osmotic pressure maintenance. Afterwards, cells were treated with 7,8-dihydromethysticin at variant concentrations viz. $0,25,50$ and $100 \mu \mathrm{mol} \mathrm{L}^{-1}$ and incubated for $24 \mathrm{~h}$. Non-migrated 
cells from upper chambers were discarded using a cotton swab and the fixation of the membrane was performed using methanol. Migrated cells were stained with crystal violet for $15 \mathrm{~min}$, washed thrice with PBS and captured under a microscope followed by washing with $32 \%$ acetic acid. Absorbance was calculated in a plate reader (EnSpire, Perkin Elmer Corporation) at $590 \mathrm{~nm}$.

\section{Determination of cell invasion through transwell chambers with Matrigel}

The effect of 7,8-dihydromethysticin on cell invasion tendency of Leukemia HL-60 cells was performed as per the abovementioned procedure except here transwell chambers were covered with Matrigel (BD Pharmingen) and Bovine serum-free medium was used.

\section{Western blot analysis for determination of expressions of JAK/STAT signalling} pathway allied proteins

After treatment of leukemia HL-60 cells with 7,8-dihydromethysticin, cells were harvested and lysed using Tris- $\mathrm{HCl}$, sodium dodecyl sulfate (SDS), mercaptoethanol, glycerol lysis buffer. Protein content was then separated using sodium dodecyl sulphate polyacrylamide gel electrophoresis (SDS-PAGE) and was transferred to hydrophilic polyvinylidene fluoride (PVDF) membranes electrophoretically. Afterwards, membranes were treated with the antibodies against JAK-1, JAK-2, STAT-1, STAT-2, p-JAK-1, p-JAK-2, p-STAT-1 and p-STAT-2 following manufacturer's guidelines. At 1:1000 dilution ratio, horseradish peroxidase-linked secondary antibodies were introduced and membranes were incubated for $2 \mathrm{~h}$ at room temperature. Membranes were then washed with PBS and visualization of immunoreactive bands was done with ECL-PLUS/Kit. $\beta$-actin was used for normalization.

\section{Statistical analysis}

The experimental data are presented as mean \pm standard deviation (SD). Data analysis was performed by one-way analysis of variance ANOVA and for multiple comparisons, the Student-Newman-Keuls test was used. $p<0.05$ was taken to show statistically significant differences.

\section{RESULTS AND DISCUSSION}

\section{Effect of 7,8-dihydromethysticin treatment on cell viability of leukemia HL-60 cells}

Leukemia treatment remains a big challenge for researchers since a higher number of side-effects, disease reoccurrence and lower survival present the key drawbacks of currently accessible treatment modalities. 7,8-Dihydromethysticin has been previously reported of inducing antiproliferative effects against different human cancer cells including colorectal cancer and osteosarcoma $(21,22)$. It was also reported to exhibit proapoptotic effects and modulated a number of cancer cell survival pathways. Herein, the effects of 7,8-dihydromethysticin (Fig. 1a) treatment on cell proliferation of leukemia HL-60 cells were evaluated. On increasing the concentrations of 7,8-dihydromethysticin viz. 0, 10, 50, 75 and $100 \mu \mathrm{mol} \mathrm{L}^{-1}$, cell viability decreased remarkably after $24 \mathrm{~h}$ and $48 \mathrm{~h}$ exposure (Fig. 1b). 7,8-Dihydromethysticin exhibited stronger inhibition of cell viability after $48 \mathrm{~h}$ time interval as compared 
a)<smiles>COC1=CC(=O)OC(CCc2ccc3c(c2)OCO3)C1</smiles>

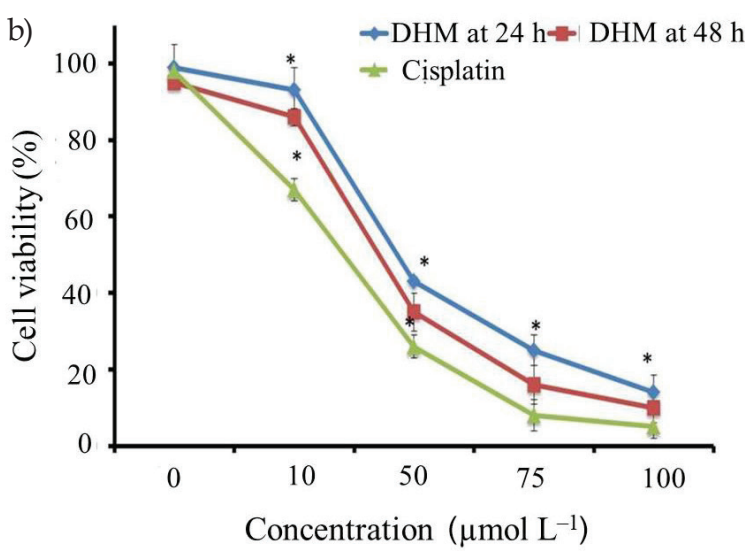

Fig. 1. a) Chemical structure of 7,8-dihydromethysticin; b) MTT viability assay was used for the determination of cell proliferation. Cisplatin (Sigma Aldrich, Mainland, China) was used as a positive control. Results indicated that 7,8-dihydromethysticin treatment in HL-60 cells had induced concentration-dependent cytotoxicity and showed significant results compared to cisplatin. All data are represented as mean \pm SD and experiments were repeated three times, $p<0.05$.

to $24 \mathrm{~h}$, thus showing time-dependent inhibition as well. Further, clonogenic assay revealed significant inhibitory effects on cell colony formation of HL-60 cells induced by 7,8-dihydromethysticin (Fig. 2a). The number of colonies calculated at $0,25,50$ and $100 \mu \mathrm{mol} \mathrm{L}^{-1}$ was

a)

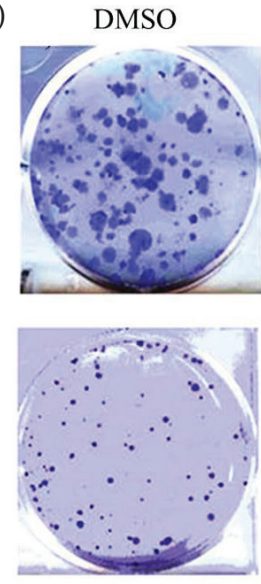

50
25
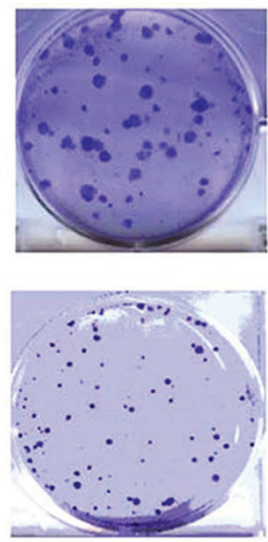

100 b)

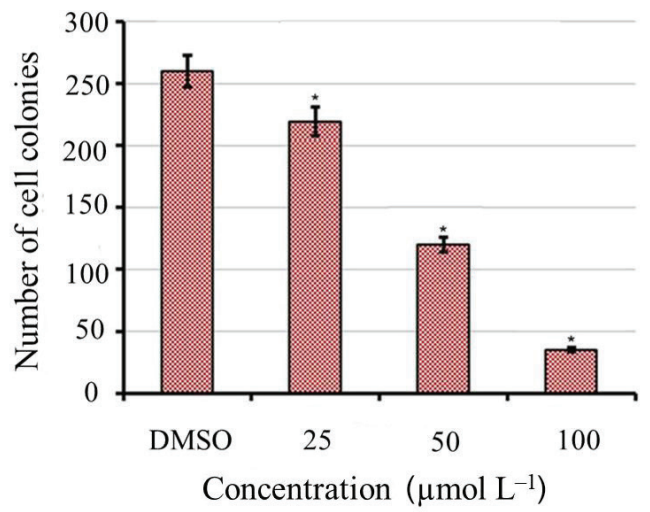

Fig. 2. Clonogenic study of HL-60 cells under a light microscope: a) results showing a decreased number of HL-60 cell colonies; b) the number of HL-60 colonies left at indicated concentrations of 7,8 -dihydromethysticin. The data are presented as mean \pm SD. ${ }^{*} p=0.05$ indicates significant variances from the control group. 
260, 225, 125 and 35, respectively (Fig. 2b). Thus, 7,8-dihydromethysticin could induce concentration-dependent inhibition of colony formation in leukemia HL-60 cells.

\section{Effect on cell cycle phase distribution}

Further, investigations were carried out to check whether the antiproliferative effects were associated with cell cycle arrest. From the last two decades, various therapeutic targets were recognised and effectively targeted in attaining therapeutic goals. These therapeutic targets include cell cycle arrest, ROS enhancement, inhibitory effects on cell invasion and migration, apoptosis, autophagy, necrosis and different signalling pathways (23-26). Previous studies have reported that 7,8-dihydromethysticin shows significant inhibitory effects on cell cycle progression as shown in the induction of G0/G1-phase cell cycle arrest in MG-63 osteosarcoma cells (21). Herein, flow cytometric analysis was carried out to unveil the impact of 7,8-dihydromethysticin exposure on cell cycle progression in leukemia HL-60 cells. Results revealed a remarkable increase in G2/M-phase cells indicating cell cycle arrest at this phase. After increasing the 7,8-dihydromethysticin concentration viz. $0,25,50$ and $100 \mu \mathrm{mol} \mathrm{L}^{-1}$, the percentage of G2/M-phase cells started to increase from 14.5, 24.2, 32.1 and $52.3 \%$ respectively (Fig. 3a). Thus, indicating a dose-reliant rise in the number of G2/M-phase cells. Further, Western blot analysis showed dose-dependent inhibition of cyclin-B1, cyclin-D1 and cyclin-E expressions (Fig. 3b). These Western blot results further validated the cell cycle inhibitory effects of 7,8-dihydromethysticin.

\section{Effects on ROS and MMP levels}

ROS and MMP play an important role in carcinogenesis as well as its suppression. Enhancement of ROS in cancer cells may cause death or any other adverse effects. MMP decrease allows the release of cytochrome-C by mitochondria into the cytoplasm giving rise to a cascade of reactions that may induce cell death. In most cases, this cell death has

a)

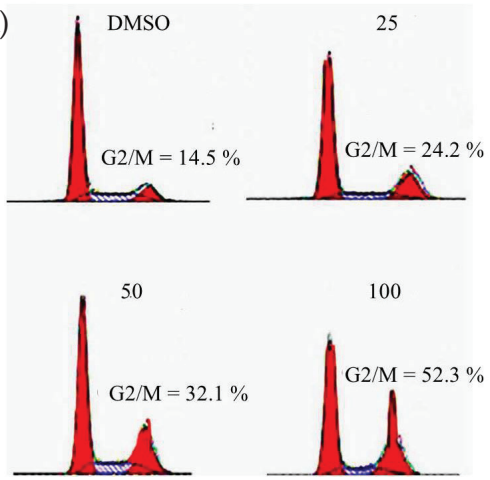

b)

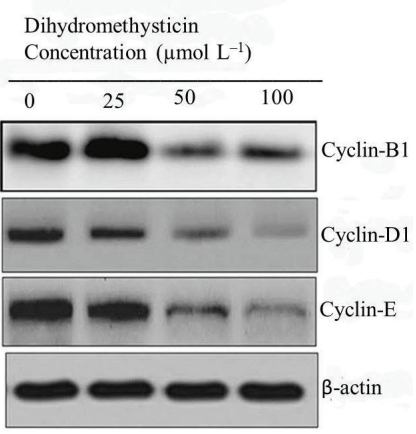

Fig. 3. Cell cycle analysis via flow cytometry: a) results indicated that 7,8-dihydromethysticin treatment to HL-60 cells induced G2/M-phase cell cycle arrest; b) Western blot assay revealed expression of cell cycle allied proteins post 7,8-dihydromethysticin treatment. Results showed inhibition of key cell cycle allied proteins (Cyclin-B1, Cyclin-D1 and Cyclin-E) as indicated. All the experiments were done in triplicates. 
a)

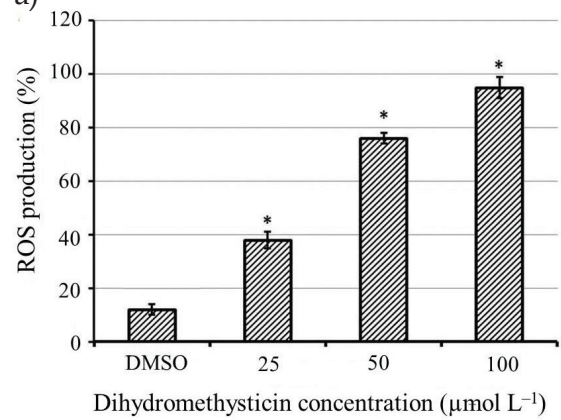

b)

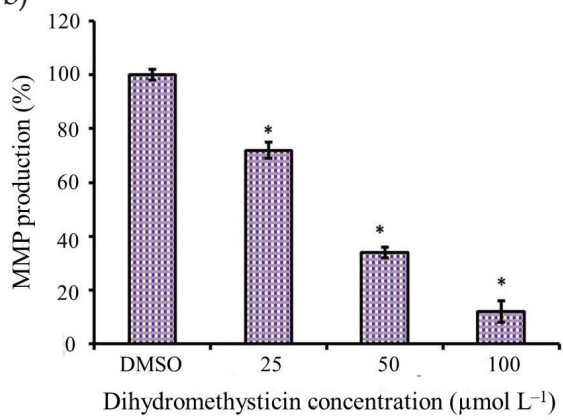

Fig. 4. ROS and MMP assessment in leukemia HL-60 cells after 7,8-dihydromethysticin treatment: a) ROS production in HL-60 cells was observed to increase after treatment with 7,8-dihydromethysticin at indicated concentrations; b) MMP in HL-60 cells was observed to decrease after treatment with 7,8-dihydromethysticin at indicated concentrations. The data are presented as the mean \pm SD. ${ }^{*} p<0.05$ indicates a significant variance from the control group.

been shown to be apoptotic cell death $(27,28)$. ROS levels were estimated via flow cytometric analysis. Results revealed an incredible increase in the levels of ROS with increasing 7,8-dihydromethysticin concentration. A concentration-dependent increase in the ROS levels was seen as depicted in Fig. 4a. Thus, ROS production increased significantly with increased 7,8-dihydromethysticin concentrations. MMP denotes the functioning of mitochondria and loss in MMP indicates a loss in mitochondrial function. Herein, MMP analysis depicted a remarkable decrease in MMP levels with increasing 7,8-dihydromethysticin concentrations exhibiting dose-dependence (Fig. 4b).

\section{Inhibitory effect of 7,8-dihydromethysticin treatment on cell migration and invasion}

The metastatic disease often proves more hazardous than a non-metastatic disease, because of the far dispersal of the disease from the origin. Therefore, cell migration and invasion play a key role in deciding the fate of malignant metastatic cancers. 7,8-Dihydromethysticin was previously reported to inhibit cell migration and invasion in human colorectal cancer cells via suppression of NLRC3/PI3K signalling (22). Herein, the cell migration tendency of leukemia HL-60 cells was assessed post-7,8-dihydromethysticin treatment. Results depicted a substantial suppression of cell migration with increased 7,8-dihydromethysticin concentrations (Fig. 5a). Transwell chambers coated with Matrigel were utilized for the estimation of 7,8-dihydromethysticin treatment on cell invasion tendency in leukemia HL-60 cells. It can be seen from the results that the number of invaded cells reduced with the increased 7,8-dihydromethysticin concentrations (Fig. 5b). Thus, both these complementary assays indicate that the tested molecule has substantial potential to inhibit cell invasion as well as cell migration in HL-60 cancer cells.

\section{Effect of 7,8-dihydromethysticin treatment on JAK/STAT signalling pathway}

The JAK/STAT pathway (Janus kinase-signal transducer and activator of transcription) is a key signalling pathway that transfers signals to the nucleus from membrane receptors. 

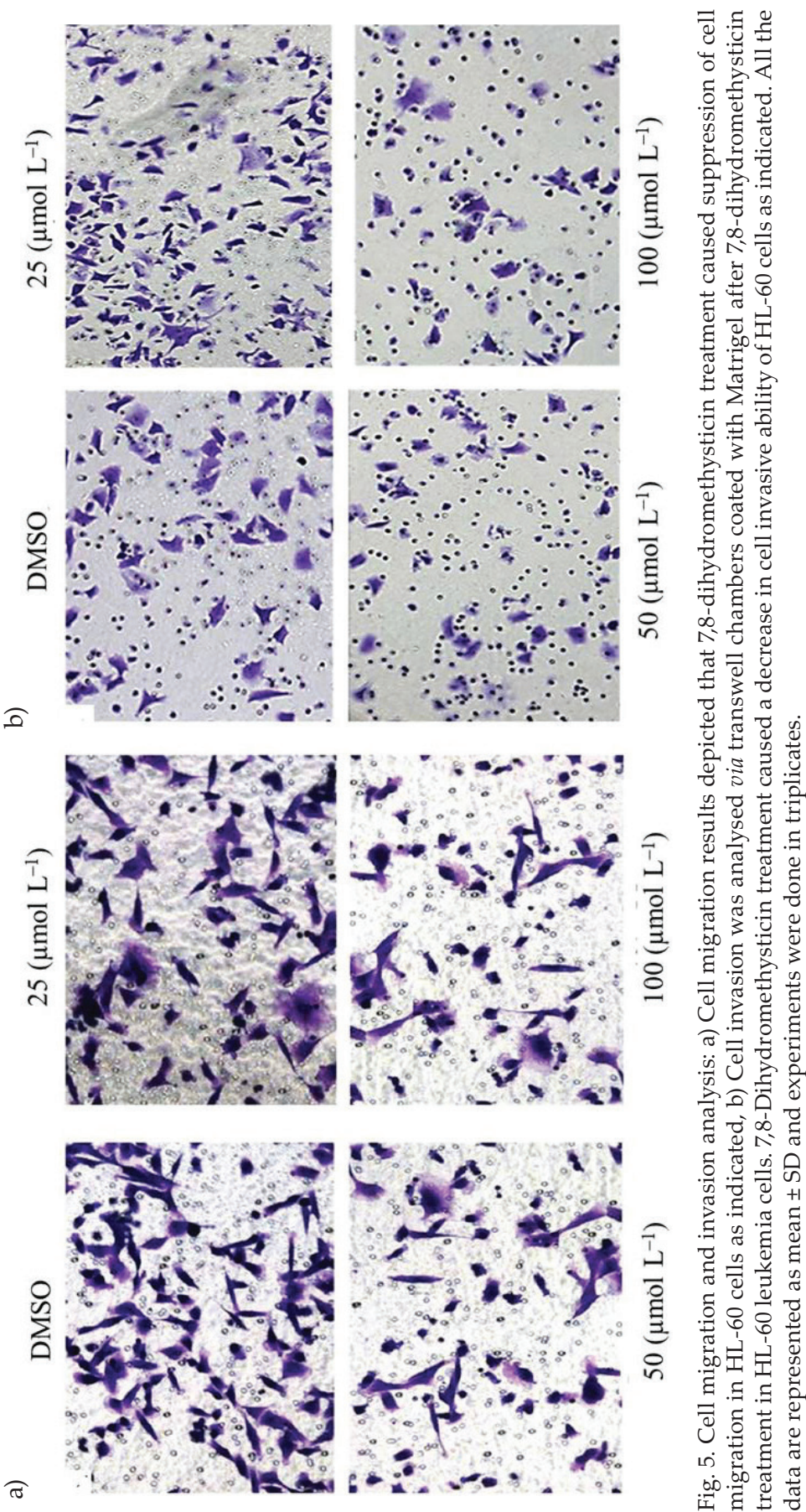


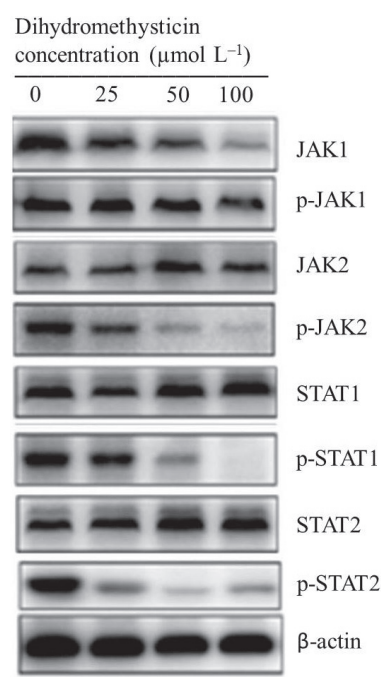

Fig. 6. Western blot analysis for the determination of effects of 7,8-dihydromethysticin treatment on the JAK/STAT signalling pathway in HL-60 leukemia cells. Results indicated inhibition of JAK-1, pJAK-1, p-JAK-2, p-STAT-1 and p-STAT-2. Actin was used for normalization.

This pathway is associated with essential growth factors and cytokines, regulating a number of cellular events including immune system development and haematopoiesis (29). Herein, the effects of 7,8-dihydromethysticin on the JAK/STAT signalling pathway were evaluated. The Western blot analysis was performed to study the impact of 7,8-dihydromethysticin treatment on JAK/STAT signalling pathway allied proteins. Results revealed that 7,8-dihydromethysticin decreased p-JAK-2, p-STAT-1, p-STAT-2 levels and increased STAT-1, STAT-2 levels (Fig. 6). This indicated 7,8-dihydromethysticin targeted the JAK/STAT signalling pathway hence contributes to its anticancer action.

\section{CONCLUSIONS}

Taking together, the abovementioned results indicate that 7,8-dihydromethysticin may be a potent antitumor agent against leukemia, as revealed by its inhibitory effects on cell cycle, cell migration and invasion as well as targeting JAK/STAT signalling pathway and enhancing ROS.

Acknowledgement. - The study was supported by the Applied Basic Research Project of Wuhan City (No. 2017060201010156).

\section{REFERENCES}

1. M. S. Tallman, D. G. Gilliland and J. M. Rowe, Drug therapy for acute myeloid leukemia, Blood $\mathbf{1 0 6}$ (2005) 1154-1163; https://doi.org/10.1182/blood-2005-01-0178

2. E. Estey and H. Dohner, Acute myeloid leukaemia, Lancet 368 (2006) 1894-1907; https://doi. org/10.1016/S0140-6736(06)69780-8 
3. J. Mao, S. Li, H. Zhao, Y. Zhu, M. Hong, H. Zhu, S. Qian and J. Li, Effects of chidamide and its combination with decitabine on proliferation and apoptosis of leukemia cell lines, Am. J. Transl. Res. 10 (2018) 2567-2578.

4. E. Jabbour, D. Thomas, J. Cortes, H. M. Kantarjian and S. O'Brien, Central nervous system prophylaxis in adults with acute lymphoblastic leukemia: current and emerging therapies, Cancer 116 (2010) 2290-300; https://doi.org/10.1002/cncr.25008

5. M. D. Kraszewska, M. Dawidowska, T. Szczepański and M. Witt, T-cell acute lymphoblastic leukaemia: recent molecular biology findings, Br. J. Haematol. 156 (2015) 303-15; https://doi.org/10.1111/ j.1365-2141.2011.08957.x

6. R. Valentin, S. Grabow and M. S. Davids, The rise of apoptosis: Targeting apoptosis in hematologic malignancies, Blood 132 (2018) 1248-1264; https://doi.org/10.1182/blood-2018-02-791350

7. K. Durinck, S. Goossens, S. Peirs, A. Wallaert, W. Van Loocke, F. Matthijssens, T. Pieters, G. Milani, T. Lammens, P. Rondou and N. Van Roy, Novel biological insights in T-cell acute lymphoblastic leukemia, Exp. Hematol. 43 (2015) 625-639; https://doi.org/10.1016/j.exphem.2015.05.017

8. S. H. Kang, S. J. Jeong, S. H. Kim, J. H. Kim, J. H. Jung, W. Koh, J. H. Kim, D. K. Kim, C. Y. Chen and S. H. Kim, Icariside II induces apoptosis in U937 acute myeloid leukemia cells: Role of inactivation of STAT3-related signaling, PLOS One 7 (2012) e28706; https://doi.org/10.1371/journal. pone.0028706

9. Y. Küley-Bagheri, K. A. Kreuzer, I. Monsef, M. Lübbert and N. Skoetz, Effects of all-trans retinoic acid (ATRA) in addition to chemotherapy for adults with acute myeloid leukaemia (AML) (nonacute promyelocytic leukaemia (non-APL), Cochrane Database of Systematic Reviews 8 (2018) Cd011960; https://doi.org/10.1002/14651858.CD011960.pub2

10. L. Mei, E. P. Ontiveros, E. A. Griffiths, J. E. Thompson, E. S. Wang and M. Wetzler, Pharmacogenetics predictive of response and toxicity in acute lymphoblastic leukemia therapy, Blood Rev. 29 (2015) 243-249; https://doi.org/10.1016/j.blre.2015.01.001

11. S. Samala and C. Veerasham, Ehanced bioavalibity of glimepiride in the presence of boswellic acids in streptozotocin-induced diabetic rat model, Nat. Prod. Chem. Res. 1 (2013) 116.

12. S. G. D. Oliveira, E. Piva and R. G, Lund The PO possibility of Interactions between medicinal herbs and allopathic medicines used by patients attended at basic care units of the Brazilian unified health system, Nat. Prod. Chem. Res. 3 (2015) 171; http://dx.doi.org/10.4172/2329-6836.1000171

13. G. M. Cragg and D. J. Newman, Biodiversity: A continuing source of novel drug leads, Pure Appl. Chem. 77 (2005) 7-24.

14. C. Kim and B. Kim, Anti-cancer natural products and their bioactive compounds inducing ER stress-mediated apoptosis: A Review, Nutrients 10 (2018) 1021; https://doi.org/10.3390/nu10081021

15. R. A. Maplestone, M. J. Stone and D. H. Williams, The evolutionary role of secondary metabolitesA review, Gene 115 (1992) 151-157; https://doi.org/10.1016/0378-1119(92)90553-2

16. S. Russmann, B. H. Lauterburg, Y. Barguil, E. Choblet, P. Cabalion, K. Rentsch and M. Wenk, Traditional aqueous kava extracts inhibit cytochrome P450 1A2 in humans: protective effect against environmental carcinogens, Clin. Pharmacol. Ther. 77 (2005) 453-454; https://doi. org/10.1016/j.clpt.2005.01.021

17. Y. Ma, K. Sachdeva, J. Liu, M. Ford, D. Yang, I. A. Khan, C. O. Chichester and B. Yan, Desmethoxyyangonin and dihydromethysticin are two major pharmacological kavalactones with marked activity on the induction of CYP3A23, Drug. Metab. Dispos. 32 (2004) 1317-1324; https://doi.org/10.1124/ dmd.104.000786

18. J. Walden, J. von Wegerer, U. Winter, M. Berger and H. Grunze H, Effects of kawain and dihydromethysticin on field potential changes in the hippocampus, Prog. Neuro-Psychopharmacol. Biol. Psychiatry 21 (1997) 697-706. 
19. J. Sarris, E. Laporte and I. Schweitzer, Kava: A comprehensive review of efficacy, safety, and psychopharmacology, Aust. N. Z. J. Psychiatry 45 (2011) 27-35; https://doi.org/10.3109\%2F00048674.2010.522554

20. Y. N. Singh and N. N. Singh, Therapeutic potential of kava in the treatment of anxiety disorders, Mol. Diag. Ther. 16 (2002) 731-743; https://doi.org/10.2165/00023210-200216110-00002

21. J. Q. Dai, Y. G Huang and A. N. He, Dihydromethysticin kavalactone induces apoptosis in osteosarcoma cells through modulation of PI3K/Akt pathway, disruption of mitochondrial membrane potential and inducing cell cycle arrest, Int. J. Clin. Exp. Pathol. 8 (2015) 4356-4366.

22. H. Pan, F. Liu, J. Wang, et al. Dihydromethysticin, a natural molecule from Kava, suppresses the growth of colorectal cancer via the NLRC3/PI3K pathway, Mol. Carcinog. 59 (2020) 575-589; https:// doi.org/10.1002/mc.23182

23. M. D. Megonigal, E. F. Rappaport, D. H. Jones, C. S. Kim, P. C. Nowell, B. J. Lange and C. A. Felix, Panhandle PCR strategy to amplify MLL genomic breakpoints in treatment-related leukemias, Proc. Natl. Acad. Sci. 94 (1997) 11583-11588; https://doi.org/10.1073/pnas.94.21.11583

24. A. S. Sreedhar and P. Csermely, Heat shock proteins in the regulation of apoptosis: new strategies in tumor therapy: a comprehensive review, Pharmacol. Ther. 101 (2004) 227-257; https://doi. org/10.1016/j.pharmthera.2003.11.004

25. K. Zhang, A. N. Ezemaduka, Z. Wang, H. Hu, X. Shi, C. Liu, X. Lu, X. Fu, Z. Chang and C. C. Yin, A novel mechanism for small heat shock proteins to function as molecular chaperones, Sci. Rep. 5 (2015) 8811; https://doi.org/10.1038/srep08811

26. W. Tang and G. Zhao, Small molecules targeting HIF-1 $\alpha$ pathway for cancer therapy in recent years, Bioorg. Med. Chem. 332 (2013) 275-285; https://doi.org/10.1016/j.bmc.2019.11523 5

27. A.O. Oyewole, M. C. Wilmot, M. Fowler and M. A. Birch-Machin, Comparing the effects of mitochondrial targeted and localized antioxidants with cellular antioxidants in human skin cells exposed to UVA and hydrogen peroxide, FASEB J. 28 (2014) 485-494; https://doi.org/10.1096/fj.13237008

28. F. Wang, X. Ye, D. Zhai, W. Dai, Y. Wu, J. Chen and W. Chen, Curcumin-loaded nanostructured lipid carrier induced apoptosis in human HepG2 cells through activation of the DR5/caspasemediated extrinsic apoptosis pathway, Acta Pharm. 70 (2020) 227-237; https://doi.org/10.2478/acph2020-0003

29. F. Seif, M. Khoshmirsafa, H. Aazami, M. Mohsenzadegan, G. Sedighi and M. Bahar, The role of JAK-STAT signaling pathway and its regulators in the fate of T helper cells, Cell Commun. Signal. 15 (2017) 23; https://doi.org/10.1186/s12964-017-0177-y 